\title{
Increasing Trends in Orthopedic Fellowships Are Not due to Inadequate Residency Training
}

\author{
K. A. Almansoori ${ }^{1}$ and M. Clark $^{2}$ \\ ${ }^{1}$ Department of Educational Psychology, University of Alberta, Edmonton, AB, Canada T6G $2 G 5$ \\ ${ }^{2}$ Division of Orthopaedic Surgery, Department of Surgery, University of Calgary, Calgary, AB, Canada T2N 4N1 \\ Correspondence should be addressed to M. Clark; drmarciaclark@gmail.com
}

Received 5 June 2014; Accepted 29 December 2014

Academic Editor: Bruce Keith

Copyright $\odot 2015$ K. A. Almansoori and M. Clark. This is an open access article distributed under the Creative Commons Attribution License, which permits unrestricted use, distribution, and reproduction in any medium, provided the original work is properly cited.

\begin{abstract}
Orthopedic residents have one of the highest fellowship participation rates among medical specialities and there are growing concerns that inadequate residency training may be contributing to this trend. Therefore, a mixed-exploratory research survey was distributed to all 148 graduating Canadian orthopedic residents to investigate their perceptions and attitudes for pursuing fellowships. A response rate of $33 \%(n=49)$ was obtained with the majority of residents undertaking one (27\%) or two (60\%) fellowships. Surgical-skill development was reported as the most common motivating factor, followed by employment and marketability; malpractice protection and financial reasons were the least relevant. The overwhelming majority of residents (94\%, $n=46)$ felt adequately prepared by their residency training for independent general practice, and $84 \%(n=41)$ of respondents did not feel that current fellowship trends were due to poor residency training. Three common themes were expressed in their comments: the growing perceived expectation by healthcare professionals and employers to be fellowship-certified, the integration of fellowship training into the surgical education hierarchy, and the failure of residency training curriculums to accommodate for this trend. In conclusion, Canadian orthopedic residents are confident of their residency training and are increasingly pursuing fellowships to primarily develop their surgical skills and expertise.
\end{abstract}

\section{Introduction}

The current structure of residency training is based on the framework established by William Halsted in the 1800s by which a new medical-school graduate undergoes a series of apprenticeships under different surgeons to acquire the knowledge and skills necessary for independent practice [1]. Upon graduating from a residency program, a graduate can either begin independent general practice or pursue additional 1-2 years of subspecialization training known as a fellowship. This optional training period first became popular in the 1970s and, since that time, the number of residents pursuing fellowships has dramatically increased across all medical specialities [1-3]. Currently, fellowship participation rates vary by surgical subspeciality with approximately 70 $75 \%$ of general surgery and urology residents pursuing fellowships, compared to over $90 \%$ of orthopedic residents
$[1,4,5]$. Unfortunately, even though orthopedics is shown to have exceedingly high fellowship enrollment rates, very few studies have investigated this phenomenon [1-3, 6-8].

As residents increasingly undertake fellowships, their decisions have strong implications to future healthcare workforce planning and graduate surgical education. There are strong concerns that as more residents enroll in fellowship programs, the educational value of residency training may become undermined: Fellowships may simply represent a "de facto" extension of residency training into a 6-year undertaking, with fellows performing more resident-level duties and residents themselves being suboptimally trained with the mindset that any skill deficits can be learned later during their fellowship period $[3,7]$. Of course, having more fellowship-trained specialists is appealing when considering that certain surgical procedures have better productivity and clinical outcomes when performed by a fellowship-trained 
surgeon $[6,7,9,10]$. However, producing an excessive number of subspecialists can lead to a poor distribution of general orthopedic services, particularly in the setting of limited healthcare resources and smaller-community accessibilities $[2,3,7]$. This is especially true when recognizing that over the last two decades, the number of specialist orthopedic surgeons has continued to increase while the number of practicing general orthopaedic surgeons has continuously decreased $[6,7,11]$. Therefore, understanding why residents are increasingly pursuing fellowships is important for the administration of future healthcare services as well as surgical education programs.

Previous studies have identified several factors guiding residents to pursue fellowships and include financial incentives and opportunities related to subspecialization, the medical malpractice environment by which certification may provide greater litigation protection, the preference for fellowship-trained surgeons at many academic institutions, a generally greater awareness among residents of patient outcomes and lifestyle factors, and employment opportunities related to subspecialization $[6,7,12-15]$. Likewise, demographic factors, like the female gender, residents from community-based programs, international medical graduates, and residents with prior graduate degrees (e.g., masters or doctoral degrees), have also been correlated with a greater likelihood of pursuing a fellowship $[2,16,17]$. However, a more recent controversial factor has been the quality and adequacy of surgical residency training with concerns that residents may be pursuing fellowships to compensate for poor surgical training [18]. Insufficient clinical experience due to stringent work-hour restrictions and increasingly nonclinical administrative tasks and academic responsibilities have meant that residents now experience lower surgicalcase volumes than their predecessors $[1,13,19-21]$. In fact, up to one-fourth of resident's duty hours are now spent on noneducational administrative activities like medicolegal and insurance documentation [22]. Likewise, rapid advancements in surgical techniques and technologies have meant that residents must also master a greater number of skills and instruments within a more limited time-frame [1]. While no national or federal residency-work regulations have been implemented in Canada, working hours are generally limited by provincial administration to approximately 80 hours per week, similar to the 2003 Accreditation Council for Graduate Medical Education guidelines in the USA [21, 23]. Overall, these factors have all led to growing concerns that residents are now primarily pursuing fellowships to compensate for inadequate surgical training and experience $[19,20]$.

Therefore, a cross-sectional research study using mixedexploratory survey methods was undertaken to investigate this subject among all graduating Canadian orthopedic residents. We assumed that inadequate surgical training was the primary reason that residents were increasingly pursuing fellowships. Overall, we expected the information from this study to help shape the future administration and design of orthopaedic residency and fellowship educational training programs, as well as influencing graduate surgical education funding and healthcare workforce planning.

\section{Methods}

2.1. Study Design. A mixed-exploratory research project with descriptive statistical and correlative data analysis was undertaken to investigate the perceptions and motivations among Canadian orthopedic residents for pursuing a fellowship. We assumed that the primary reason residents were pursuing fellowships was due to inadequate surgical residency training, the qualification of adequacy being a resident's subjective confidence in their ability to undertake independent practice as a general orthopedic surgeon. Ethical approval for the study was obtained from the Human Ethics Research Office at the University of Alberta. A two-stage research study was developed with the first stage involving the use of qualitative interviews and pilot studies to develop a mixed-exploratory survey form. The second stage involved the distribution and collection of the surveys for descriptive, inductive, and correlative statistical analysis.

2.2. Survey Design and Protocol. A qualitative interview was performed with four final-year orthopedic residents to provide the content validity and framework for developing a concise and relevant survey. The participants were recruited by convenience sampling from a single institution, the University of Alberta. Confidential semistructured interviews provided in-depth narratives regarding why fellowships were attractive to Canadian orthopedic residents. Using the etic data, a mixed-exploratory survey was developed. Factors impacting their decision to pursue a fellowship were listed into seven categories and residents were asked to rank/order their selections in terms of priority. Dichotomous questions relating fellowship-certification to residency training, employment issues, and clinical practice were included. The surveys were then piloted by convenience sampling at a Canadian orthopedic review course to 15 final-year residents from various Canadian residency programs. Based on their responses and comments, the survey was revised and finalized into a 16-item questionnaire containing fifteen quantitative questions and one qualitative question (see appendix). The finalized anonymous cross-sectional surveys were then distributed to all Canadian orthopedic residency programs in late April 2013. A letter of transmittal, an anonymous survey, and a postage paid return-envelope were provided to all participants.

2.3. Sampling Calculation and Methods. The target populations were postgraduate year- 4 and year-5 Canadian orthopedic residents (PGY-4 and PGY-5) who were within 14 months of graduating from their residency programs. According to the 2012 online Canadian Residency Match System (CaRMS) data, there are approximately 74 orthopaedic residents annually matching to residency programs in Canada [21, 24]. Therefore, we estimated a total population of 148 PGY-4 and PGY-5 orthopedic residents in Canada and used Raosoft sample size calculations (Raosoft Inc., Seattle, WA, USA) with a $10 \%$ sampling error, a 50\% response distribution, and a $95 \%$ confidence level, to determine a sample size requirement of 47 participants. This decision to include PGY-4 residents was based on the following factors: residents must be interviewed 
and commit to a fellowship within the first half of their PGY4 year, residents who are within 14 months of completing their training are better suited to judge their confidence and preparation for independent practice, and concerns of recall bias in their decisions to pursue a fellowship can be relatively minimized [25-27].

2.4. Outcomes Measures and Analysis. The primary objective was to identify, in terms of priority, the reasons that Canadian orthopaedic residents are increasingly pursuing fellowships. The secondary objectives were to investigate the perceptions and attitudes among residents for pursuing fellowships as well as establishing whether a correlation existed between the adequacy of a resident's graduate surgical education and their decision to participate in a fellowship. The data was summarized using descriptive statistics and statistically analyzed using Statistical Package for the Social Sciences 12.0 (SPSS, Chicago, USA). Two-tailed paired $t$-tests were used to compare fellowship-motivation selections and chi-square tests were used to analyze correlations among contingency tables. A $P$ value of $<0.05$ was considered statistically significant. Qualitative data from resident's comments were categorized into several category headings (e.g., surgical education, social expectations, recommendations, etc.). Subjective responses were discussed between the authors and inductive generalizations and conclusions were synthesized from participants' responses.

\section{Results}

3.1. Response Rates and Demographics. In total, 49 surveys were completed out of a total estimated population of 148 Canadian PGY-4 and PGY-5 residents, providing a 33\% response rate in keeping with other similar studies [10]. Eight residents provided qualitative comments on the subject of current fellowship trends. The majority of respondents $(88 \%$, $n=42$ ) were pursuing a fellowship, with only one resident undecided (2\%) and 6 residents not pursuing a fellowship (11\%). Interestingly, almost half $(n=24)$ of the respondents claimed they had no intention of pursuing a fellowship prior to starting their orthopedic residency. The vast majority of respondents were males $(78 \%, n=38)$, and females were significantly more likely to pursue a fellowship $(P<0.05$; $95 \% \mathrm{CI})$. In fact all of the female respondents $(n=11)$ were pursuing fellowships, with the majority (63\%) pursuing two and sports medicine being their most common selection. No residents were pursuing more than two fellowships (see Figure 1).

3.2. Fellowship Selections. Of the available fellowship specialities, arthroplasty was the most common selection $(43 \%, n=$ $18)$, followed by sports medicine (40\%) and pediatrics $(21 \%)$ (see Figure 2). Hand (4\%) and oncology (4\%) were the least popular fellowship selections. All residents, pursuing either trauma $(n=8)$, foot and ankle $(n=5)$, upper extremity $(n=$ $4)$, oncology $(n=2)$, or limb-deformity $(n=1)$ fellowships, were also pursuing a second fellowship. The selections were difficult to interpret because a majority of the responses

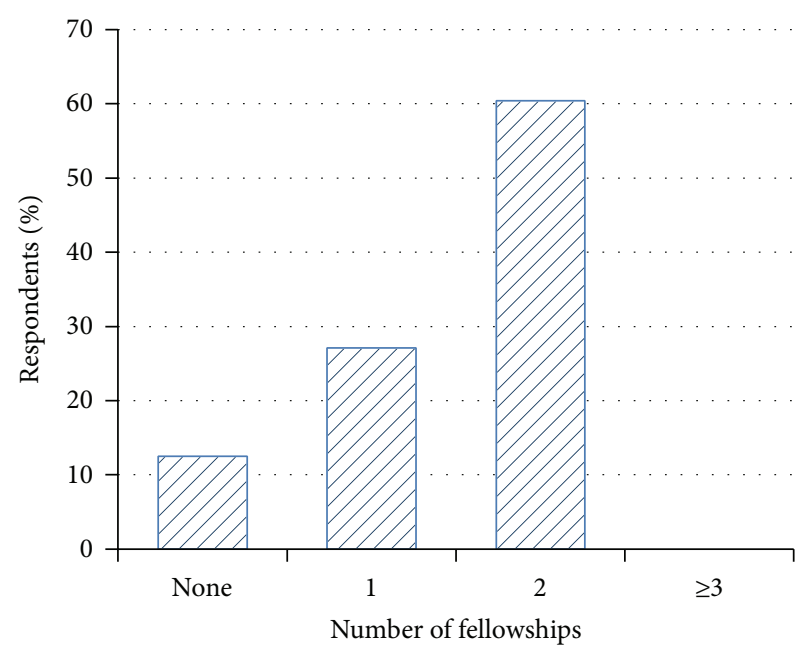

FIGURE 1: Number of fellowships being pursued by PGY-4 and PGY5 respondents. Graphic illustration of survey responses demonstrating $11 \%(n=6)$ residents not pursuing any fellowships, $27 \%$ $(n=13)$ pursuing a single fellowship, and $60 \%(n=29)$ pursuing two fellowships. No respondents were pursuing more than two fellowships.

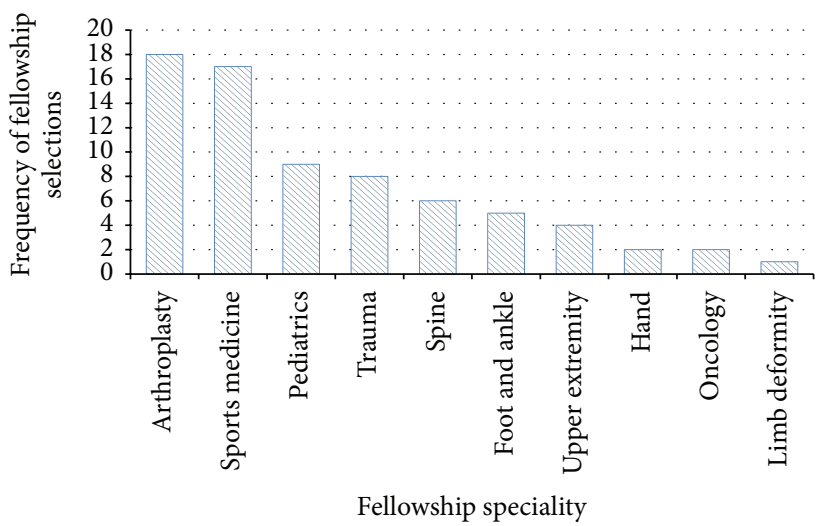

FIGURE 2: Fellowship pursuits among current PGY-4 and PGY-5 orthopedic residents. Graphic illustration of various frequencies of fellowship selections among current PGY-4 and PGY-5 Canadian orthopedic residents.

involved two fellowship selections and we could not establish which fellowship-speciality was dominant or primary. In general, residents were much more likely to undertake two fellowships of different specialities (e.g., pediatrics followed by a spine fellowship) than to pursue two fellowships of the same speciality (e.g., two consecutive pediatric fellowships). In fact, only $5 \%(n=2)$ of residents were pursuing two fellowships of the same speciality. Residents, who were only pursuing a single fellowship, ranked sports medicine as their most popular selection $(n=7)$, followed by arthroplasty $(n=5)$ and pediatrics $(n=2)$. Female residents selected sports medicine, followed by pediatrics and arthroplasty, as their preferred fellowships, and there was a greater tendency for females to perceive expectations to be fellowship-certified $(P=0.08)$. 


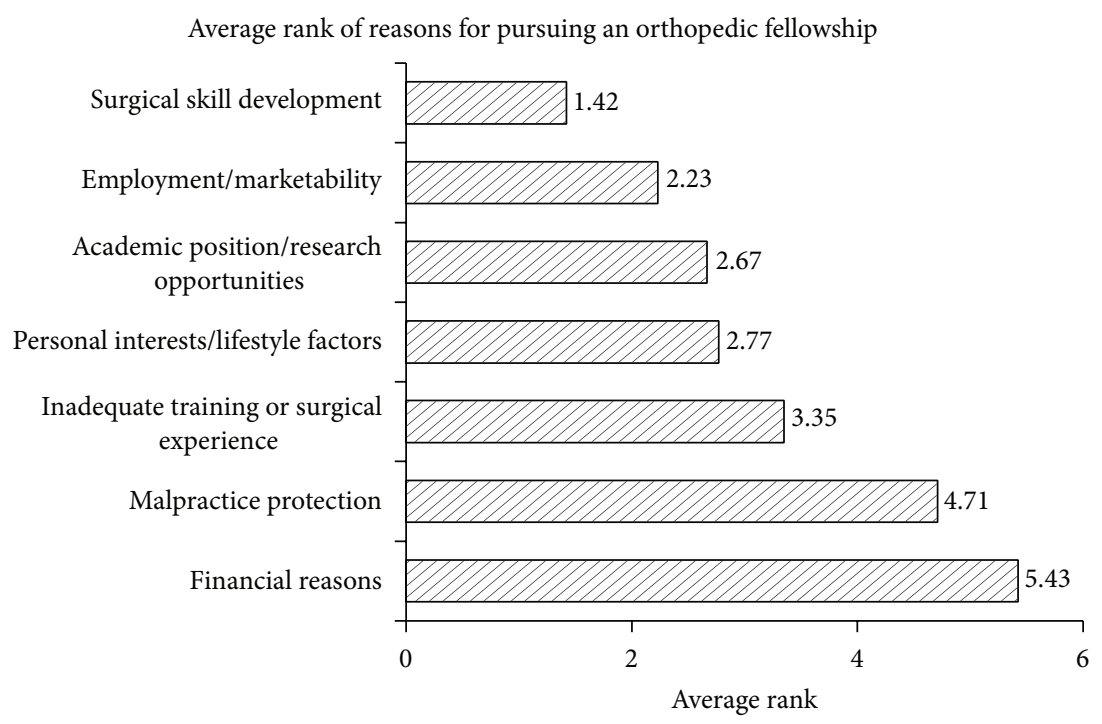

FIGURE 3: Average ranking of selected reasons for pursuing a fellowship. Horizontal bar-chart reporting the average rank in descending order of selected reasons among respondents for pursuing an orthopedic fellowship (a rank of 1 representing the highest priority and 7 representing the lowest priority).

3.3. Fellowship Motivations and Objectives. Approximately $62 \%(n=26)$ of residents selected "skill development" as their number one reason for pursuing a fellowship and $90 \%$ ranked it among their top-three reasons (average rank 1.42) (see Figure 3 ). The second most commonly reported reason was "employment opportunities or marketability" (average rank of 2.23), with 76\% $(n=32)$ of residents ranking it among their top-three reasons. Both "personal interests or lifestyle factors" and "academic appointment or research opportunities" were equally selected as the third most common motivating factor $(P>0.10 ; 95 \% \mathrm{CI})$. Financial reasons were considered the least important reason for pursuing a fellowship (average rank 5.43). Regarding the subject of "inadequate surgical training or experience," the majority of residents did not select this as an important factor, with only $12 \%(n=5)$ of residents ranking this factor among their top-three reasons for pursuing a fellowship.

3.4. Residency Training. Respondents overwhelmingly felt that they were adequately trained by their residency programs to practice as a general orthopedic surgeon $(94 \%, n=46)$ (see Figure 4$)$. In fact, only $16 \%(n=8)$ of participants felt that the current fellowship trends were due to inadequate surgical residency training, with over $63 \%$ indicating that even if they were guaranteed an employment position as a general orthopedic surgeon, they would still specialize and pursue a fellowship. Likewise, even if residency programs were lengthened by another 1-2 years or if the current residency training curricula were changed to a competencybased system, the majority of respondents stated they would still pursue a fellowship. No statistical correlation was found between a respondent's decision to pursue a fellowship and the perceived quality of their residency training $\left(\chi^{2}[1, n=\right.$ $48]=0.45, P=0.5)$.
3.5. Fellowship Certification. Approximately one-third (31\%, $n=15$ ) of residents felt that fellowship-certification should be considered a licensing requirement to perform certain surgical procedures. Also, while the majority of respondents felt that there was an expectation to be fellowship-certified among healthcare employers $(74 \%, n=29)$ and other health professionals (59\%), only $41 \%$ of residents considered that patients held similar expectations (see Figure 5).

3.6. Resident Comments. The open-ended invitation for residents to express their opinions and comments on the increasing prevalence of fellowship-certification yielded 11 replies, of which only 8 were felt to be informative or relevant. A review of the comments highlighted three underlying themes: the integration of fellowship training into the orthopedic educational hierarchy, the growing expectation to obtain fellowship certification, and the need for residency training programs to accommodate for this trend. With regard to the first theme, several comments were made about residency training no longer being recognized as a sufficient qualification of competency to be an orthopedic surgeon. Residents stated that fellowships had essentially become an "extension" of their residency training and had been considered a "complementary degree" or "qualification after residency." Likewise, the expectation to be fellowship-certified was also a recurring theme in over half of the comments. Several participants felt that fellowship-certification was necessary to find employment at "big centers" or "famous hospitals," with many remarks that the increasing trend was not related to a "lack of training" but to appeal to "market demands" for more "expert-training." Finally, two residents offered suggestions to improve the framework of current residency programs; the first suggestion was to shorten the duration of residency training so that residents "can go off and do more 


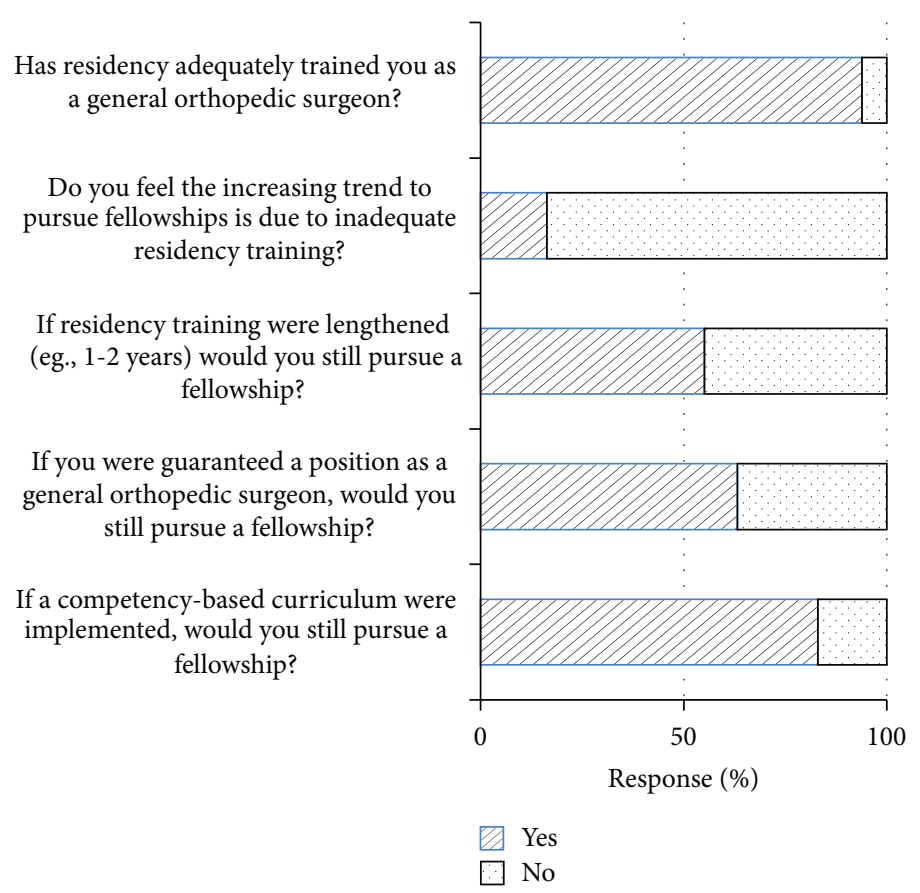

FIGURE 4: Graphic illustration of responses to various fellowship questions. Horizontal percentage-stacked bars demonstrating the confidence of residents in their residency training with very few considering the growing trend in fellowships a result of inadequate residency training. The majority reporting that neither the offer of employment nor changes to the duration or curriculum of their residencies would dissuade them from pursuing a fellowship.

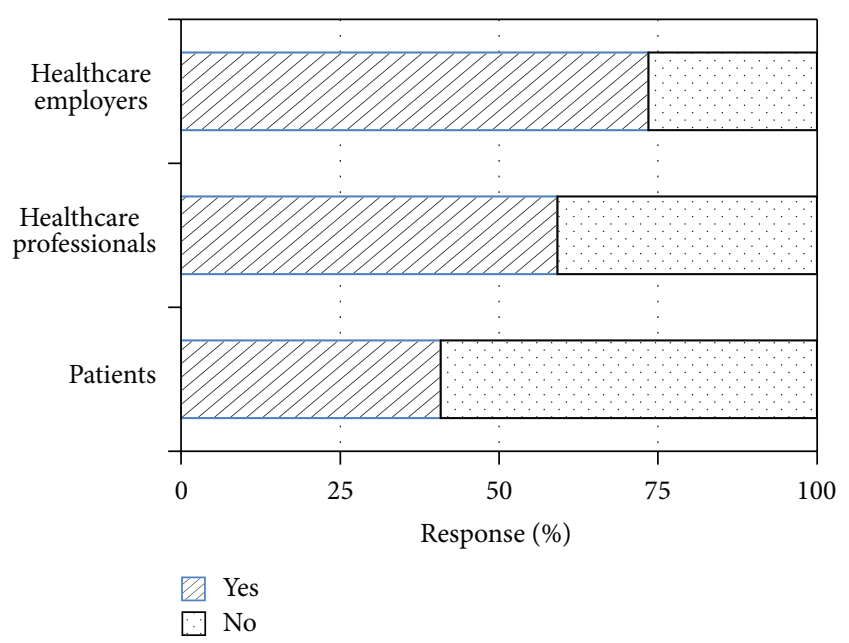

FIGURE 5: Expectations of fellowship-certification by category, as perceived by residents. Horizontal percentage-stacked bars illustrating resident perceptions on whether various populations expected them to be fellowship-certified. Residents considered healthcare employers to be the most likely population to require fellowshipcertification from them.

fellowships" and the second was to allow residents to "select focused rotations during [their] last year" so that they could obtain a fellowship certificate upon graduation. Overall, the comments echoed similar themes to the responses generated from the quantitative questions in the survey.

\section{Discussion}

The decision to pursue a fellowship is complex and multifactorial, but it has important implications to healthcare workforce planning and the future design and organization of graduate medical education programs. Training surgical residents for independent practice has become increasingly challenging due to the growing volume of administrative and nonsurgical academic activities that residents are expected to perform within a more stringent work-hour time period $[1,13,19-21]$. Considering these obstacles, we assumed that the primary reason why Canadian orthopedic residents were increasingly pursuing fellowships was due to inadequate residency training. The survey results fail to validate this assertion and, instead, suggest that a resident's desire to develop and improve their surgical skills is the primary reason for the increasing fellowship trends. In fact, residents generally reported that neither the offer of employment nor changes to the duration or organization of their residency training would dissuade them from pursuing fellowships. These findings highlight a likely misinterpretation between a resident's need for additional training due to poor residency training (i.e., inadequate-training) and their desire for specialized training in order to master surgical techniques not available at their home institutions (i.e., expert-training). Overall, the survey responses provide preliminary evidence to illustrate that the growing trend in fellowships among Canadian residents is not due to inadequate surgical training, but a combination of more personal and occupational factors which require further investigation. 
In general, orthopedic residents have one of the highest fellowship participation rates in medicine with approximately $90 \%$ of graduating residents enrolling in fellowship programs [4]. Interestingly, over half of our respondents claimed they originally had no intentions of pursuing a fellowship prior to starting residency. This finding is consistent with another study by Vick and Borman which found that while only $33 \%$ of first-year general surgery residents were interested in pursuing a fellowship, the proportion significantly increased during residency due to a greater awareness of the benefits and opportunities related to fellowship-certification [9]. Nevertheless, similar to other studies on the subject, the personal desire to develop better surgical skills was ranked as the most common reason for pursuing a fellowship and residents are universally pursuing higher qualifications with one study reporting a $122 \%$ increase in master's or doctoral degree enrollments by residents $[2,3,6,7,9,10]$. As noted in the participants' comments, some would like training institutions to acknowledge this trend and possibly incorporate fellowship-certification or research degrees into their residency training curriculum. This concept is not new; until the early 1990s vascular surgery specialization was only offered at a fellowship training level until several general surgery programs began offering a direct vascular training pathway known as an "early specialization program" (ESP) $[16,28,29]$. These programs have now been shown to improve surgical training experience across cardiac, vascular, and pediatric surgery specialities and have had strong positive feedback from both residents and faculty members [29]. In orthopedics, excluding the degree of podiatry which does not require a medical-doctorate degree, no officially accredited ESPs are available to residents who wish to directly enter subspecialization. Therefore, introducing ESPs in fields like spine or pediatric orthopedics may allow residents to develop and specialise their skills without the need for fellowships, a model which may prove financially advantageous in terms of surgical education funding and work-force planning.

Employment and marketability factors were reported as the second most common reason for pursuing a fellowship with the majority of residents perceiving strong expectations from hospital employers and other healthcare professionals to be fellowship-certified. These perceptions are supported by the fact that many academic centers require their instructors to hold fellowship-certification and that employment positions for fellowship-certified specialists have increased $325 \%$ over the last two decades $[6,23,30-$ 32]. Surprisingly, residents did not feel that patients held similar expectations which may be due to the assumption that patients are unfamiliar with surgical training qualifications and, therefore, are unlikely to select their surgeons based on fellowship certification. Interestingly, malpractice protection and financial factors were reported as the least important factors for pursuing a fellowship $[4,10]$. However, this may be expected when considering that there is little evidence to suggest that fellowship-certification provides malpractice protection [6] or that fellowship specialization is financially beneficial: average income earnings of pediatric or foot and ankle specialists are significantly lower than those of general orthopedic surgeons [33].
Based on our survey results, $60 \%$ of Canadian residents are pursuing at least two fellowships, compared with only $8 \%$ of American residents; arthroplasty, sports medicine, and pediatrics were the three most popular fellowship choices, and hand and oncology fellowships were the least favourite [4]. These findings are similar to those reported by American residents except for hand surgery, which was ranked as their third most popular selection and is likely due to differences in practice settings where the majority of hand surgeons in Canada are plastic surgeons while those in the USA are predominantly orthopedic surgeons [11, 34-37]. Of course, reliable comparisons between American and Canadian orthopedic residents may be challenging when considering the unique practice environments facing these two populations $[4,6,23,30-32]$. All residents pursuing trauma, foot and ankle, or oncology fellowships were shown to be pursuing a second fellowship-speciality. Among the residents who were pursuing two fellowships, the majority of the combinations were complementary and were typically anatomically divided (e.g., hand fellowships tended to accompany upper extremity fellowships). These "combined-fellowships" have only recently become recognized by accrediting institutions and, over time, may prove more popular than conventional singlespeciality fellowship programs, especially when considering the current trend to perform two fellowships.

Overall, several limitations were encountered in this study and can be divided into sampling and survey issues. An ideal sample size to meet a $95 \%$ confidence level would have required 108 participants, a challenging number to enroll due to the small estimated population size $(N=148)$ of current graduating PGY-4 and PGY-5 Canadian orthopedic residents. Furthermore, because the surveys were distributed during a transition period (i.e., PGY-4 residents are entering their chief year and PGY-5 residents are preparing for their certification examinations), circumstantial factors may have influenced their responses. Likewise, asking final-year PGY-5 residents about their decision to pursue a fellowship may be subject to recall bias since the decision is typically made at the beginning of the PGY-4 year. Furthermore, due to resource constraints, we were able to neither pilot nor provide a French language translation of the survey to French speaking Canadian residents. In the future, investigating why some residents were not pursuing fellowships may provide equally important information on the subject. In general, while this study provides a preliminary understanding of the perceptions and motivations guiding Canadian orthopedic residents to pursue fellowships, the final decision is undoubtedly complex and multifactorial.

\section{Conclusions}

Approximately $87 \%$ of Canadian orthopedic residents are pursuing fellowships with almost two-thirds undertaking two fellowships. The three most popular fellowship programs were arthroplasty, sports medicine, and pediatrics, while the least popular were oncology and hand surgery. Survey results suggest that inadequate residency training is not primarily responsible for the increasing trend in fellowship participation and that surgical-skill development 
and financial incentives were the most and least relevant motivating factors, respectively. In general, residents perceive strong expectations from healthcare employers and other health professionals to be fellowship-certified, but less as commonly from patients. Overall, three underlying themes are expressed among respondents: the growing expectation to be fellowship-certified, the integration of fellowships into the orthopedic training hierarchy, and the need for educational institutions to recognize this trend.

\section{Appendix}

\section{Sample Survey Distributed to Canadian Orthopedic Residents}

Fellowship Survey for PGY-4 and PGY-5 Orthopedic Residents. Please fill out as many of the following questions as possible and add any comments you would like to. We read them all and everything you write will remain anonymous.

(1) What is your gender?

$$
\begin{aligned}
& \text { [ ] Male } \\
& \text { [ ] Female }
\end{aligned}
$$

(2) Will you pursue a fellowship(s)?

$$
\begin{aligned}
& {[\text { ] Yes }} \\
& \text { [ ] No } \\
& \text { [ ] Undecided }
\end{aligned}
$$

(3) Did you intend on pursuing a fellowship prior to starting residency?

$$
\begin{aligned}
& \text { [ ] Yes } \\
& \text { [ ] No }
\end{aligned}
$$

(4) How many fellowships are you pursuing?

- (Please provide a number, not a range.)

(5) Which fellowship-speciality(s) are you pursuing?

$$
\begin{aligned}
& \text { - Arthroplasty } \\
& \text { - Foot and ankle } \\
& \text { - Hand } \\
& \text { - Oncology } \\
& \text { - Pediatrics } \\
& \text { - Spine } \\
& \text { - Sports medicine } \\
& \text { - Trauma } \\
& \text { - Other: - }
\end{aligned}
$$

(6) Why are you pursuing a fellowship? (Please number these choices 1-7 from highest (1) to lowest (7) priority, write N/A if the option is not a consideration, or use "Other" for additional reasons not listed.)
- Employment/marketability

- Academic position/research opportunities

- Skill development (e.g., exposure to different techniques, etc.)

- Inadequate residency training/surgical experience

- Financial reasons

- Malpractice protection

- Personal interest/lifestyle factors

- Other: -

(7) Has your residency program adequately trained you for practice as a general orthopaedic surgeon?

$$
\begin{aligned}
& \text { [ ] Yes } \\
& \text { [ ] No }
\end{aligned}
$$

(8) Do you think that the increasing trend of residents pursuing fellowships is an indicator of the poor quality of residency training?

$$
\begin{aligned}
& \text { [ ] Yes } \\
& \text { [ ] No }
\end{aligned}
$$

(9) If you were guaranteed a position as a general orthopedic surgeon upon residency completion, would you still pursue a fellowship?

$$
\begin{aligned}
& \text { [ ] Yes } \\
& \text { [ ] No }
\end{aligned}
$$

(10) If residency training were lengthened (e.g., 1-2 additional years) to allow for more surgical exposure, would you still pursue a fellowship?

$$
\text { [ ] Yes }
$$

(11) If you are familiar with the concept, would you still pursue a fellowship if a competency-based training curriculum were implemented?

$$
\begin{aligned}
& \text { [ ] Yes } \\
& \text { [ ] No }
\end{aligned}
$$

(12) Should fellowship-certification be considered a licensing requirement to perform certain orthopaedic procedures?

$$
\begin{aligned}
& \text { [ ] Yes } \\
& \text { [ ] No }
\end{aligned}
$$

(13) Do you feel that fellowship-certification is becoming an expectation among the following.

\section{(A) Health Professionals?}

[ ] Yes
[ ] No 
(B) Patients?

$$
\text { [ ] Yes }
$$

(C) Healthcare employers?

$$
\text { [ ] Yes }
$$

(14) Please provide any additional comments on the popularity or role of fellowships in orthopedic surgery: ....

\section{Conflict of Interests}

The authors declare that they have no competing interests related to this paper. No commercial, financial, or material interests or supports were requested or obtained for this study. No personal interests or relationship conflicts are known to bias our work. Both authors approve of the undertaking, methodology, and conclusions of this study and agree with its submission for publication.

\section{References}

[1] C. A. Pellegrini, A. L. Warshaw, and H. T. Debas, "Residency training in surgery in the 21st century: a new paradigm," Surgery, vol. 136, no. 5, pp. 953-965, 2004.

[2] K. R. Borman, L. R. Vick, T. W. Biester, and M. E. Mitchell, "Changing demographics of residents choosing fellowships: longterm data from the American Board of Surgery," Journal of the American College of Surgeons, vol. 206, no. 5, pp. 782-789, 2008.

[3] A. Sarmiento, "The projected shortage of orthopaedists may be our fault," Journal of Bone and Joint Surgery, Series A, vol. 94, no. 14, article e105, 2012.

[4] S. Hariri, S. C. York, M. I. O’Connor, B. S. Parsley, and J. C. McCarthy, "A resident survey study of orthopedic fellowship specialty decision making and views on arthroplasty as a career," Journal of Arthroplasty, vol. 26, no. 6, pp. 961-968, 2011.

[5] B. Welk, R. Kodama, and A. Macneily, "The newly graduated canadian urologist: over-trained and underemployed?" Journal of the Canadian Urological Association, vol. 7, no. 1, pp. E10-E15, 2013.

[6] N. T. Morrell, D. M. Mercer, and M. S. Moneim, "Trends in the orthopedic job market and the importance of fellowship subspecialty training," Orthopedics, vol. 35, no. 4, pp. e555-e560, 2012.

[7] M. T. Nousiainen, D. A. Latter, D. Backstein, F. Webster, and K. A. Harris, "Surgical fellowship training in Canada: what is its current status and is improvement required?" Canadian Journal of Surgery, vol. 55, no. 1, pp. 58-65, 2012.

[8] H. Yeo, K. Viola, D. Berg et al., "Attitudes, training experiences, and professional expectations of US general surgery residents: a national survey," The Journal of the American Medical Association, vol. 302, no. 12, pp. 1301-1308, 2009.

[9] L. R. Vick and K. R. Borman, "Instability of fellowship intentions during general surgery residencies," Journal of Surgical Education, vol. 65, no. 6, pp. 445-452, 2008.

[10] J. R. Schiller and C. W. DiGiovanni, "Foot and ankle fellowship training: a national survey of past, present, and prospective fellows," Foot and Ankle International, vol. 29, no. 1, pp. 34-41, 2008.
[11] S. Kakar, K. Bakri, and A. Y. Shin, "Survey of hand surgeons regarding their perceived needs for an expanded upper extremity fellowship," Journal of Hand Surgery, vol. 37, no. 11, pp. 2374.e3-2380.e3, 2012.

[12] T. E. Adamson, D. C. Baldwin Jr., T. J. Sheehan, and A. A. Oppenberg, "Characteristics of surgeons with high and low malpractice claims rates," Western Journal of Medicine, vol. 166, no. 1, pp. 37-44, 1997.

[13] W. C. Allen, "The relationship between residency programs and fellowships in the educational setting," Clinical Orthopaedics and Related Research, no. 257, pp. 57-60, 1990.

[14] G. P. Kohn and M. Nikfarjam, "The effect of surgical volume and the provision of residency and fellowship training on complications of major hepatic resection," Journal of Gastrointestinal Surgery, vol. 14, no. 12, pp. 1981-1989, 2010.

[15] B. J. McGrory, B. S. Bal, S. York, W. Macaulay, and D. B. McConnell, "Surgeon demographics and medical malpractice in adult reconstruction," Clinical Orthopaedics and Related Research, vol. 467, no. 2, pp. 358-366, 2009.

[16] M. C. Ellis, B. Dhungel, R. Weerasinghe, J. T. Vetto, and K. Deveney, "Trends in research time, fellowship training, and practice patterns among general surgery graduates," Journal of Surgical Education, vol. 68, no. 4, pp. 309-312, 2011.

[17] T. J. Leibrandt, S. A. Fassler, and J. B. Morris, "Attrition and replacement of general surgery residents," Surgical Clinics of North America, vol. 84, no. 6, pp. 1525-1535, 2004.

[18] D. K. Nakayama and S. M. Taylor, "SESC practice committee survey: surgical practice in the duty-hour restriction era," The American Surgeon, vol. 79, no. 7, pp. 711-715, 2013.

[19] E. M. Bucholz, G. R. Sue, H. Yeo, S. A. Roman, R. H. Bell Jr., and J. A. Sosa, "Our trainees' confidence: results from a national survey of 4136 US general surgery residents," Archives of Surgery, vol. 146, no. 8, pp. 907-914, 2011.

[20] T. J. Leibrandt, C. M. Pezzi, S. A. Fassler, E. F. Reilly, and J. B. Morris, "Has the 80-hour work week had an impact on voluntary attrition in general surgery residency programs?" Journal of the American College of Surgeons, vol. 202, no. 2, pp. 340-344, 2006.

[21] M. Sudarshan, W. C. Hanna, M. H. Jamal, L. H. P. Nguyen, and S. A. Fraser, "Are Canadian general surgery residents ready for the 80-hour work week? A nationwide survey," Canadian Journal of Surgery, vol. 55, no. 1, pp. 53-57, 2012.

[22] K. J. Brasel, A. L. Pierre, J. A. Weigelt et al., "Resident work hours: what they are really doing," Archives of Surgery, vol. 139, no. 5, pp. 490-494, 2004.

[23] "Demand high but medical specialists not finding work in Canada," http://news.nationalpost.com/2011/09/19/demandhigh-but-medical-specialists-not-finding-work-in-canada/.

[24] "Canadian Resident Matching Service-R1 Iteration Orthopedic Surgery Information," https://phx.e-carms.ca/phoenix-web/ $\mathrm{pd} / \mathrm{main}$ ?mitid=1161\#.

[25] M. H. Erdelyi, “The ups and downs of memory," The American Psychologist, vol. 65, no. 7, pp. 623-633, 2010.

[26] O. D. Williamson, B. J. Gabbe, A. M. Sutherland, and M. J. Hart, "Does recall of preinjury disability change over time?" Injury Prevention, vol. 19, no. 4, pp. 238-243, 2013.

[27] H. Schmolck, E. A. Buffalo, and L. R. Squire, "Memory distortions develop over time: recollections of the O.J. Simpson trial verdict after 15 and 32 months," Psychological Science, vol. 11, no. 1, pp. 39-45, 2000. 
[28] S. C. Stain, "How to change general surgery residency training," Advances in Surgery, vol. 45, no. 1, pp. 275-284, 2011.

[29] S. C. Stain, T. W. Biester, J. B. Hanks et al., "Early tracking would improve the operative experience of general surgery residents," Annals of Surgery, vol. 252, no. 3, pp. 445-451, 2010.

[30] "Royal College speaks out about unemployed specialist doctors in Canada," http://www.royalcollege.ca/common/documents/ news/2012/unemployed_specialist_doctors_media_release_oct 2012_e.pdf.

[31] Canadian Medical Association, "Where have all the orthopedic surgery jobs gone?” Canadian Medical Association, Clinical News Bulletin, June 2012.

[32] B. Goldman, "Will operate for food? The unemployed doctor paradox," CBC Radio Blog: White Coat, Black Art, 2012.

[33] T. Gaskill, C. Cook, J. Nunley, and R. C. Mather, "The financial impact of orthopaedic fellowship training," Journal of Bone and Joint Surgery, Series A, vol. 91, no. 7, pp. 1814-1821, 2009.

[34] Hand Surgery, http://www.plasticsurgery.ca/hand.php.

[35] P. J. Stern, "Subspecialty certification in hand surgery," Clinical Orthopaedics and Related Research, vol. 449, pp. 165-168, 2006.

[36] J. P. Higgins, "The diminishing presence of plastic surgeons in hand surgery: a critical analysis," Plastic and Reconstructive Surgery, vol. 125, no. 1, pp. 248-260, 2010.

[37] S. Hariri, S. C. York, M. I. O'Connor, B. S. Parsley, and J. C. McCarthy, "Career plans of current orthopaedic residents with a focus on sex-based and generational differences," Journal of Bone and Joint Surgery, Series A, vol. 93, no. 5, article e16, 2011. 

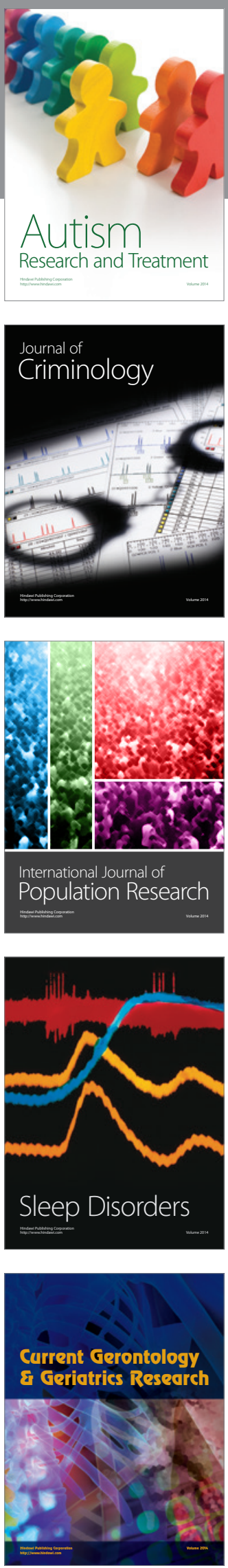
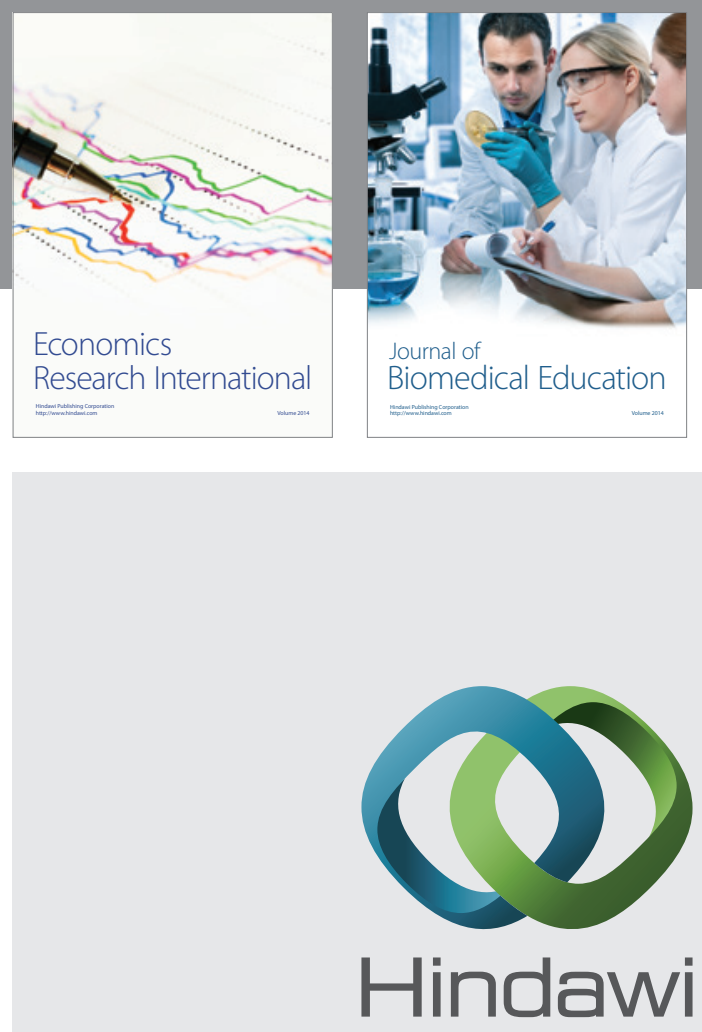

Submit your manuscripts at

http://www.hindawi.com
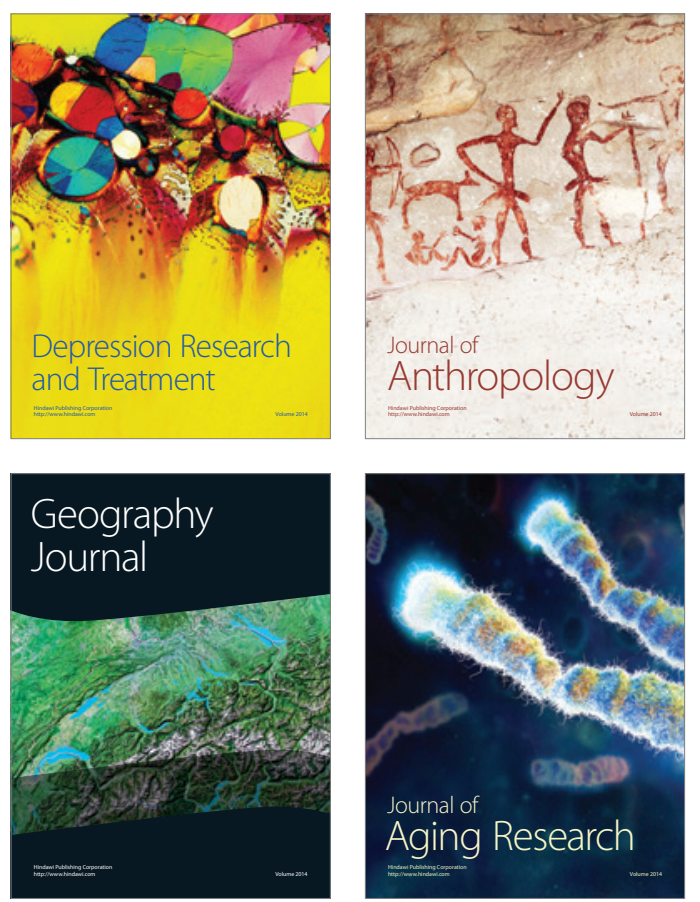
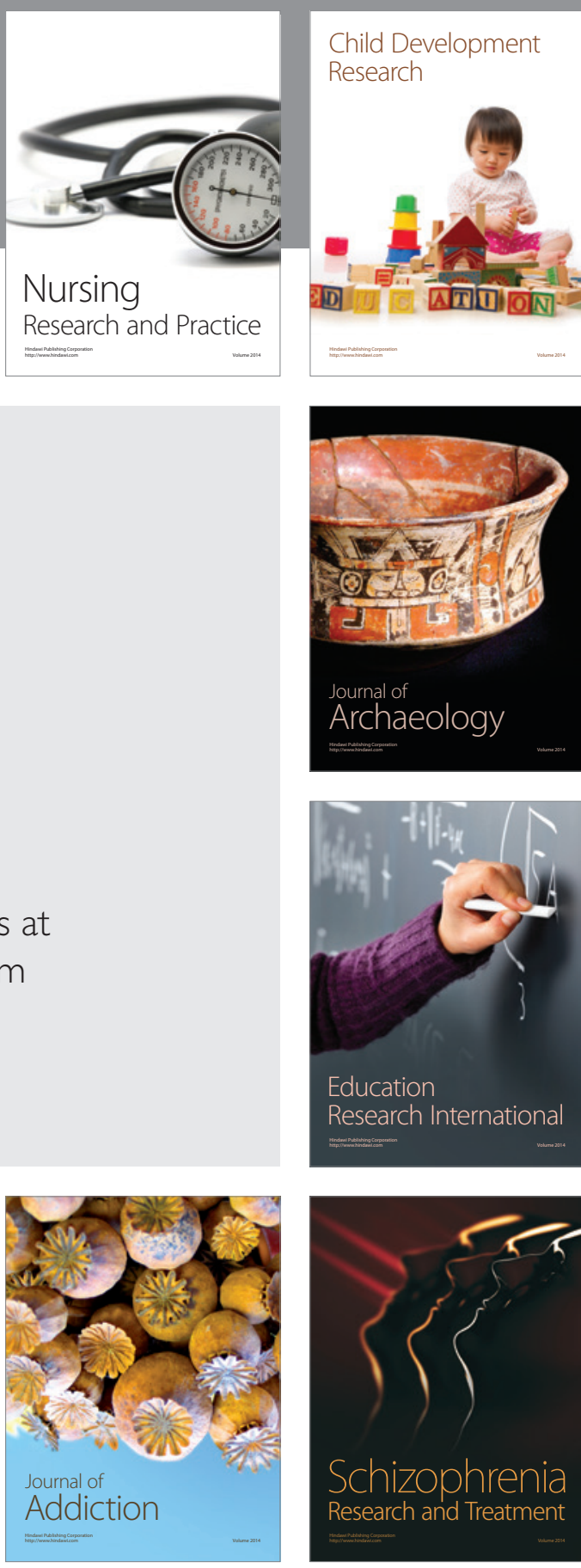

(D)
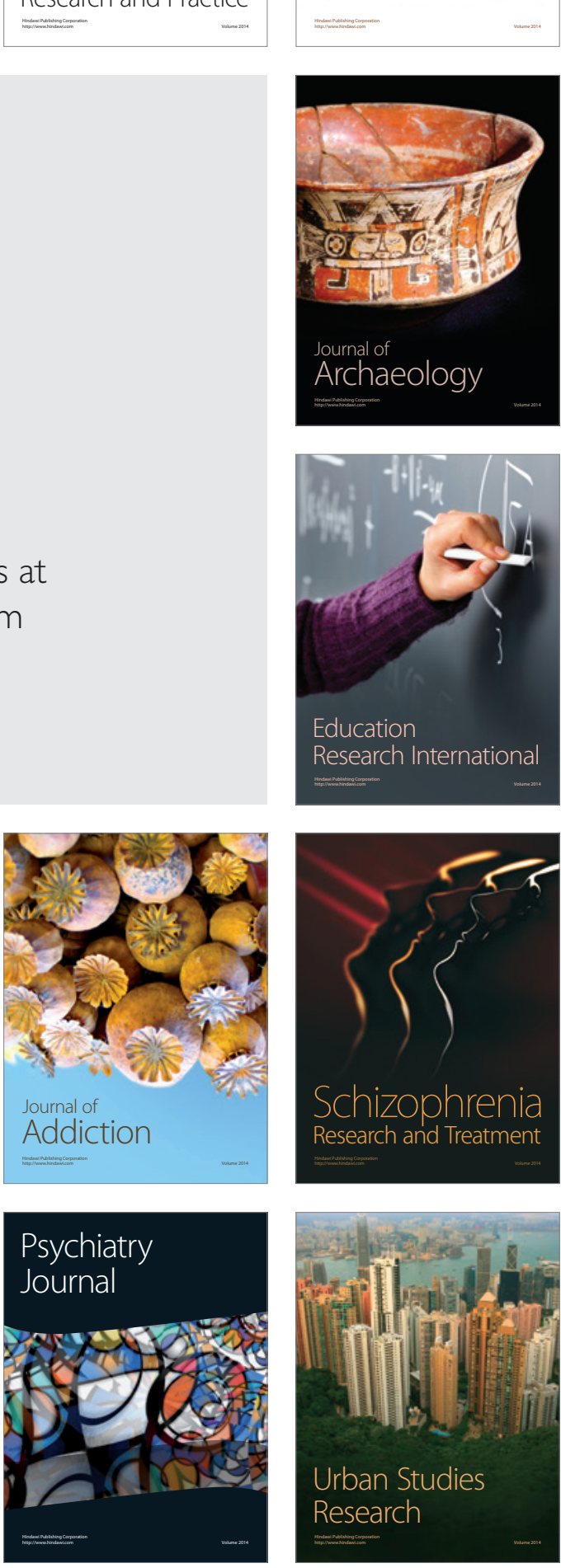